Cite this: Dalton Trans., 2014, 43 11221

Received 11th February 2014, Accepted 5th May 2014

DOI: $10.1039 / c 4 d t 00440 j$

www.rsc.org/dalton

\section{Americium(III) and europium(III) complex formation with lactate at elevated temperatures studied by spectroscopy and quantum chemical calculations $\uparrow$}

\author{
Astrid Barkleit, ${ }^{a, b}$ Jerome Kretzschmar, ${ }^{a}$ Satoru Tsushima ${ }^{a}$ and Margret Acker $^{c}$ \\ Thermodynamic parameters for the complex formation of Am(III) and Eu(III) with lactate were determined \\ with UV-vis and time-resolved laser-induced fluorescence spectroscopy (TRLFS) in a temperature range \\ between 25 and $70{ }^{\circ} \mathrm{C}$. The reaction enthalpy decreased with increasing ionic strength. ATR FT-IR and \\ NMR spectroscopy in combination with density functional theory (DFT) calculations revealed structural \\ details of the Eu(III) lactate 1:1 complex: a chelating coordination mode of the lactate with a monodentate \\ binding carboxylate group and the hydroxyl group being deprotonated.
}

\section{Introduction}

Small organic molecules, which can bind heavy metal ions, are ubiquitous in nature. They can be found in nearly all biological systems like microorganisms, plants and animals as a product of various biochemical processes. They are also part of organic matter of argillaceous rocks, which are potential host rocks for nuclear waste repositories.

The understanding of the complex formation behavior of radionuclides with such small organic molecules and the thermodynamic quantification of the interaction is of great importance to simulate and predict their migration behavior in the environment. Especially data at elevated temperatures are crucial, because not only in various organisms but particularly in the near field of nuclear waste disposals higher temperatures are prevailing. ${ }^{1}$

We investigated the complex formation and thermodynamic data of Am(III) and its non-radioactive analogue lanthanide $\mathrm{Eu}$ (III) with lactate. Lactate was selected as a representative ubiquitous small organic molecule that exists as metabolite in all organisms and also in significant amounts in clay rock formations. ${ }^{2}$ Experiments were performed at ambient and elevated temperatures with time-resolved laser-induced fluorescence spectroscopy (TRLFS), and for Am(III) additionally

\footnotetext{
${ }^{a}$ Institute of Resource Ecology, Helmholtz-Zentrum Dresden - Rossendorf, P.O. Box 510119,01314 Dresden, Germany.E-mail: a.barkleit@hzdr.de

${ }^{b}$ Radiochemistry, Department of Chemistry and Food Chemistry, Technische Universität Dresden, 01062 Dresden, Germany

${ }^{c}$ Central Radionuclide Laboratory, Technische Universität Dresden, 01062 Dresden, Germany

$\dagger$ Electronic supplementary information (ESI) available. See DOI: 10.1039/c4dt00440j
}

with UV-vis spectrometry. Furthermore, spectroscopic investigations concerning structural features have been carried out for $\mathrm{Eu}$ (III) lactate with attenuated total reflection Fourier transform infrared (ATR FT-IR) spectroscopy and nuclear magnetic resonance (NMR) spectroscopy, supported by calculations with density functional theory (DFT).

For the $\mathrm{Eu}(\mathrm{III})$ as well as the Am(III) lactate system, several investigations have been published ( $\left.\mathrm{Eu}(\mathrm{III}),{ }^{3-12} \mathrm{Am}(\mathrm{III})^{3,10,13-15}\right)$. But studies about the complex formation behavior at trace metal concentration, lower ionic strength and higher temperatures, which are important parameters influencing the migration behavior of radionuclides in the environment, are still missing. The proposed combination of methods is highly suitable to fill this gap. TRLFS as a sensitive and selective technique has been extensively used to analyze actinide and lanthanide complex formation with inorganic and organic ligands at trace metal concentrations. ${ }^{16,17}$ The application of TRLFS onto Am(III) complexation was up to now limited because of its much lower luminescence intensity and much shorter lifetime in comparison to $\mathrm{Cm}$ (III) or $\mathrm{Eu}(\mathrm{III})$. Some publications about TRLFS with Am(III) at ambient ${ }^{18-26}$ or low temperatures ${ }^{22}$ exist, but no studies at elevated temperatures have been published until now.

Some structural suggestions for the $\mathrm{Eu}(\mathrm{III})$ lactate, which do exist are only assumptions from indirect methods. ${ }^{4,5,12}$ In this work, we want to provide direct structural information. ATR FT-IR spectroscopy combined with calculations of structure and spectroscopic data using DFT gives useful information about structural features as it has been shown previously for the $\mathrm{Eu}(\mathrm{III})$ complexes with pyromellitic and citric acid. ${ }^{27,28}$ Lanthanide induced shifts in NMR spectroscopy as caused by the interaction of nuclear spins with electronic unpaired spins can be used as a helpful tool for signal separation, probing the potential binding sites and structure including geometries and distances. ${ }^{29}$ 
The combination of all these methods should offer new insights concerning the structure of the Eu(III) lactate complex thereby resolving contradicting suggestions in the previous works whether the hydroxyl group is protonated or not. ${ }^{4,5,12,30}$

\section{Experimental}

\section{Solutions and reagents}

Na-L-lactate (Fluka) and $\mathrm{EuCl}_{3} \cdot 6 \mathrm{H}_{2} \mathrm{O}$ (Aldrich) were used without further purification. Am-243 was supplied by the Oak Rich National Laboratory as $\mathrm{AmO}_{2}$. The oxide was dissolved in $\mathrm{HNO}_{3}$ and then aliquoted for experiments. The purity of the isotope was verified by $\alpha$ - and $\gamma$-spectrometry. Only the daughter nuclide of $\alpha$-decay, Np-239 (half-life: $2.355 \mathrm{~d}$ ), in equilibrium was determined (about $0.0001 \%$ of Am). For experiments except NMR, solutions were prepared with deionized water, the ionic strength was adjusted with $\mathrm{NaClO}_{4}$ or $\mathrm{NaCl}$ (Merck) to $0.1 \mathrm{M}$. Necessary pH adjustments were done with $\mathrm{NaOH}$ and $\mathrm{HClO}_{4}$ or $\mathrm{HCl}$ with an accuracy of 0.05 units. For NMR experiments, deuterated chemicals (all purchased from Sigma-Aldrich) were used. $\mathrm{D}_{2} \mathrm{O}$ (99.9 atom\% D) was used as solvent and pD was adjusted by diluted solutions of $\mathrm{NaOD}$ (40 wt\% in $\mathrm{D}_{2} \mathrm{O}, 99.5$ atom\% D) and $\mathrm{DCl}\left(35 \mathrm{wt} \%\right.$ in $\mathrm{D}_{2} \mathrm{O}, 99$ atom $\% \mathrm{D}$ ) in $\mathrm{D}_{2} \mathrm{O}$.

\section{UV-vis measurements}

For spectrophotometric UV-vis titration, $2.5 \mathrm{~mL}$ of $5 \times 10^{-6} \mathrm{M}$ $\mathrm{Am}^{3+}$ at $\mathrm{pH} 3.0$ or 6.0 and $0.1 \mathrm{M} \mathrm{NaClO}_{4}$ were titrated with aliquots $(5,10$ or $20 \mu \mathrm{L})$ of $5 \times 10^{-3} \mathrm{M}, 1 \times 10^{-2} \mathrm{M}$ or $0.1 \mathrm{M}$ lactate solution ( $\mathrm{pH} 3.0$ or $\left.6.0,0.1 \mathrm{M} \mathrm{NaClO}_{4}\right) .21$ to 26 titration steps up to a lactate concentration of $0.1 \mathrm{M}$ were performed; every mixture was allowed to equilibrate for at least $15 \mathrm{~min}$. The measurements were carried out in a quartz cuvette with screw cap ( $1 \mathrm{~cm}$ path length). UV-vis absorption spectra were recorded in the wavelength range between 400 and $700 \mathrm{~nm}$ using a CARY G5 UV-vis-NIR spectrophotometer (Varian Inc., USA).

\section{TRLFS measurements}

For spectrophotometric TRLFS titration $2.5 \mathrm{~mL}$ of $5 \times 10^{-6} \mathrm{M}$ $\mathrm{Am}^{3+}$ or $\mathrm{Eu}^{3+}$ at $\mathrm{pH} 3.0,5.0$ or 6.0 and $0.1 \mathrm{M} \mathrm{NaClO}_{4}$ were titrated with aliquots $(5,10$ or $20 \mu \mathrm{L})$ of $5 \times 10^{-3} \mathrm{M}, 1 \times 10^{-2} \mathrm{M}$ or $0.1 \mathrm{M}$ lactate solution ( $\mathrm{pH} 3.0,5.0$ or $6.0,0.1 \mathrm{M} \mathrm{NaClO}_{4}$ ). 26 to 31 titration steps up to a lactate concentration of $0.1 \mathrm{M}$ were performed; every mixture was allowed to equilibrate for at least $15 \mathrm{~min}$. The temperature was adjusted using a stirred temperature-controlled cuvette holder (Flash $300^{\mathrm{TM}}$, Quantum Northwest, USA).

The TRLFS measurements for Am(III) were carried out with a pulsed Nd:YAG-MOPO laser system from Spectra Physics (Mountain View, USA), combined with a Spectrograph M270 and an ICCD camera system Spectrum One from Horiba-Jobin Yvon. The time difference between the trigger of the laser system and the start of the camera was adjusted by a delay generator from Spectrum One. The excitation wavelength of the laser source was varied between 503 and $508 \mathrm{~nm}$ with pulse energies of $10 \mathrm{~mJ}$. Emission spectra were recorded between 625 and $773 \mathrm{~nm}$, averaging 10 spectra with accumulating 80 laser pulses for each spectrum. The gate width of the camera was set to be $1 \mu \mathrm{s}$. The step width between two spectra in time-resolved mode was $2 \mathrm{~ns}, 50$ to 60 delay steps (up to $120 \mathrm{~ns}$ ) were measured for every sample. The spectrograph and the camera system were controlled by Spectramax from Horiba-Jobin Yvon.

The TRLFS measurements for Eu(III) were carried out with a pulsed flash lamp pumped Nd:YAG-OPO laser system from Continuum as described ${ }^{31}$ at an excitation wavelength of $394 \mathrm{~nm}$ and a gate width of $1 \mathrm{~ms}$ for all measurements. Static and time-resolved luminescence spectra of Eu(III) were recorded in the range of $565-650 \mathrm{~nm}$ (1200 lines $\mathrm{mm}^{-1}$ grating, $0.2 \mathrm{~nm}$ resolution, 2000 accumulations) and 440-780 nm (300 lines $\mathrm{mm}^{-1}$ grating, $0.7 \mathrm{~nm}$ resolution, 200 accumulations), respectively. For time-resolved measurements, 41 spectra were recorded with $20-50 \mu$ s separation.

\section{ATR FT-IR measurements}

ATR FT-IR measurements were carried out with $1 \times 10^{-2} \mathrm{M}$ lactate and $\mathrm{Eu}^{3+}$ each at $\mathrm{pH}$ 5.0. The infrared spectra were recorded at room temperature with an FT-IR spectrometer (Bruker VERTEX 80/v) equipped with a diamond ATR cell (crystal diameter: $4 \mathrm{~mm}, 9$ reflections; Smiths Inc.) and a mercury cadmium telluride detector. Details on the experimental setup are given elsewhere. ${ }^{32,33}$ For the complex species, difference spectra were calculated from single-beam spectra consecutively recorded from solutions containing the Eu(III) lactate complexes and pure lactate with the same concentration and $\mathrm{pH}$. For the experiments, an ATR flow cell (volume: $200 \mu \mathrm{L}$ ) with a constant flow rate of $200 \mu \mathrm{L} \mathrm{m^{-1 }}$ was used. Each single-beam spectrum was co-added from 128 scans at a spectral resolution of $4 \mathrm{~cm}^{-1}$.

\section{DFT calculations}

DFT calculations were performed using Gaussian 09. ${ }^{34}$ Geometries were optimized in the aqueous phase at the B3LYP level $^{35,36}$ using the PCM solvation model implemented in Gaussian program. The large core effective core potential as well as the corresponding basis set suggested by Dolg ${ }^{37}$ was used on Eu as in the previous studies. ${ }^{27,28}$ For $\mathrm{C}, \mathrm{O}$, and $\mathrm{H}$, allelectron valence triple-zeta basis set plus double polar and diffuse functions have been used. ${ }^{38}$ The final geometries were confirmed to be the energy minimum through vibrational frequency analysis where no imaginary frequency was found to be present. The spectra were fitted with the half-width of $8 \mathrm{~cm}^{-1}$ at half-height using the calculated harmonic frequencies and IR intensities.

The spin-orbit effect and multiconfigurational character of the system were neglected. The first coordination sphere around $\mathrm{Eu}$ was saturated with water molecules fixing the coordination number to 8 or 9 . The rest of the solvation shells were also considered through the use of the PCM model.

\section{NMR measurements}

NMR samples with $0.1 \mathrm{M}$ in lactate and $\mathrm{Eu}^{3+}$ concentrations ranging from 0 to $0.15 \mathrm{M}$ were prepared by the admixture of 
lactate and $\mathrm{Eu}^{3+}$ stock solutions in $\mathrm{D}_{2} \mathrm{O}$, adjusting the $\mathrm{pD}$ to 5.4 , corresponding to $\mathrm{pH} 5.0$, by addition of appropriate amounts of diluted $\mathrm{DCl}$ or $\mathrm{NaOD}$ solutions in $\mathrm{D}_{2} \mathrm{O}$. The sample containing $\mathrm{La}$ (III) instead of $\mathrm{Eu}(\mathrm{III})$ was prepared similarly. All measurements were performed on a Varian Unity Inova 400 spectrometer with a field strength of $9.4 \mathrm{~T}$ and resonance frequencies of 400 and $100 \mathrm{MHz}$ for ${ }^{1} \mathrm{H}$ and ${ }^{13} \mathrm{C}$, respectively, using an ATB ${ }^{1} \mathrm{H} /{ }^{19} \mathrm{~F} /\left\{{ }^{15} \mathrm{~N}-{ }^{31} \mathrm{P}\right\}$ PFG $5 \mathrm{~mm}$ broadband probe. For both nuclei the number of accumulations was increased, whereas the acquisition time and the relaxation delay were decreased with increasing Eu(III) concentration.

\section{Data analysis}

The infrared, absorption and luminescence spectra were analyzed using OriginPro 7.5G (OriginLab, Northhampton, MA, USA) to obtain peak positions and lifetimes (TRLFS).

Static luminescence spectra of $\mathrm{Eu}(\mathrm{III})$ have been normalized to the peak area of the ${ }^{5} \mathrm{D}_{0} \rightarrow{ }^{7} \mathrm{~F}_{1}$ transition, which is a magnetic dipole and therefore not influenced by complexation.

The fluorescence decay lifetimes were calculated by fitting the integrated luminescence signal to a sum of exponential decay functions:

$$
E(t)=\sum_{i} E_{i 0} \exp \left(-t / \tau_{i}\right)
$$

$E(t)$ is the total luminescence intensity at time $t, E_{i 0}$ the luminescence intensity of the species $i$ at the time $t=0$, and $\tau_{i}$ the corresponding decay lifetime.

The number of water molecules in the first coordination shell was determined from the luminescence lifetimes $\tau$ (in $\mathrm{ms})$. For Am(III), the empirical formula from Kimura and Kato $^{19}$ (eqn (2)), and for Eu(III), the linear relationship developed by Horrocks and Sudnick ${ }^{39}$ and the resultant empirical formula from Kimura ${ }^{40}$ (eqn (3)), were used:

$$
\begin{gathered}
n\left(\mathrm{H}_{2} \mathrm{O}\right) \pm 0.5=2.56 \times 10^{-4} \times \tau^{-1}-1.43 \text { for } \mathrm{Am}(\mathrm{III}) \\
n\left(\mathrm{H}_{2} \mathrm{O}\right) \pm 0.5=1.07 \times \tau^{-1}-0.62 \text { for } \mathrm{Eu}(\mathrm{III})
\end{gathered}
$$

The complex stability constants were determined from the absorption or luminescence spectra by using the factor analysis program specfit. ${ }^{41}$ Input parameters for the data fitting were the total concentrations of the metal ion and the ligand, the $\mathrm{pH}$, and the $\mathrm{p} K_{\mathrm{a}}$ of lactate from literature $\left(\mathrm{p} K_{\mathrm{a} 1}=3.69,{ }^{42}\right.$ $\mathrm{p} K_{\mathrm{a} 2}=11.20,{ }^{30}$ recalculated to $\left.I=0.1 \mathrm{M}\right)$. A brief description of the operation mode of this program ${ }^{43}$ and of the fitting procedure is given elsewhere. ${ }^{44}$

Thermodynamic data were calculated with the modified linear form of the van't Hoff equation:

$$
\ln K=-\frac{\Delta H}{R} \frac{1}{T}+\frac{\Delta S}{R}
$$

The extrapolation of the constants to infinite dilution, $I=0$, was done applying the Specific Interaction Theory (SIT) using the IUPAC software for Ionic Strength Corrections. ${ }^{45}$ The ion interaction parameters $\varepsilon$ were taken from ref. 46 (based on ref. $47,48)$ for $\mathrm{Eu}^{3+}, \mathrm{ClO}_{4}{ }^{-}$, from ref. 48 for $\mathrm{Am}^{3+}, \mathrm{ClO}_{4}{ }^{-}$and from ref. 48,49 for $\mathrm{Na}^{+}, \mathrm{ClO}_{4}{ }^{-}$, and $\mathrm{Na}^{+}, \mathrm{CH}_{3} \mathrm{COO}^{-}$(acetate as analog for lactate as it is proposed in ref. 50), whereas that for $\mathrm{Eu}^{3+}$, $\mathrm{Lac}^{-}$and $\mathrm{Am}^{3+}{ }^{2} \mathrm{Lac}^{-}$were calculated using the guidelines given in ref. 50. The temperature dependencies of $\varepsilon$ and the DebyeHückel parameter $B$ can be neglected. ${ }^{48,50}$ Values for the Debye-Hückel parameter $A$ as function of temperature have been calculated from literature data ${ }^{51}$ within the program. ${ }^{45}$

\section{Results and discussion}

\section{Am(III) UV-vis spectroscopy}

The absorption maximum of Am(III), usually equivalent to the excitation wavelength for fluorescence spectroscopy, namely the ${ }^{7} \mathrm{~F}_{0} \rightarrow{ }^{5} \mathrm{~L}_{6}$ transition, strongly depends on the chemical surrounding of the ion. The shift of the absorption maximum of Am(III) with lactate as ligand is depicted in Fig. 1A. For the aqueous Am(III), the absorption maximum is at $503 \mathrm{~nm}$. At the highest lactate concentration of $0.1 \mathrm{M}$ we observe a red-shift of about $3 \mathrm{~nm}$ to $506 \mathrm{~nm}$.
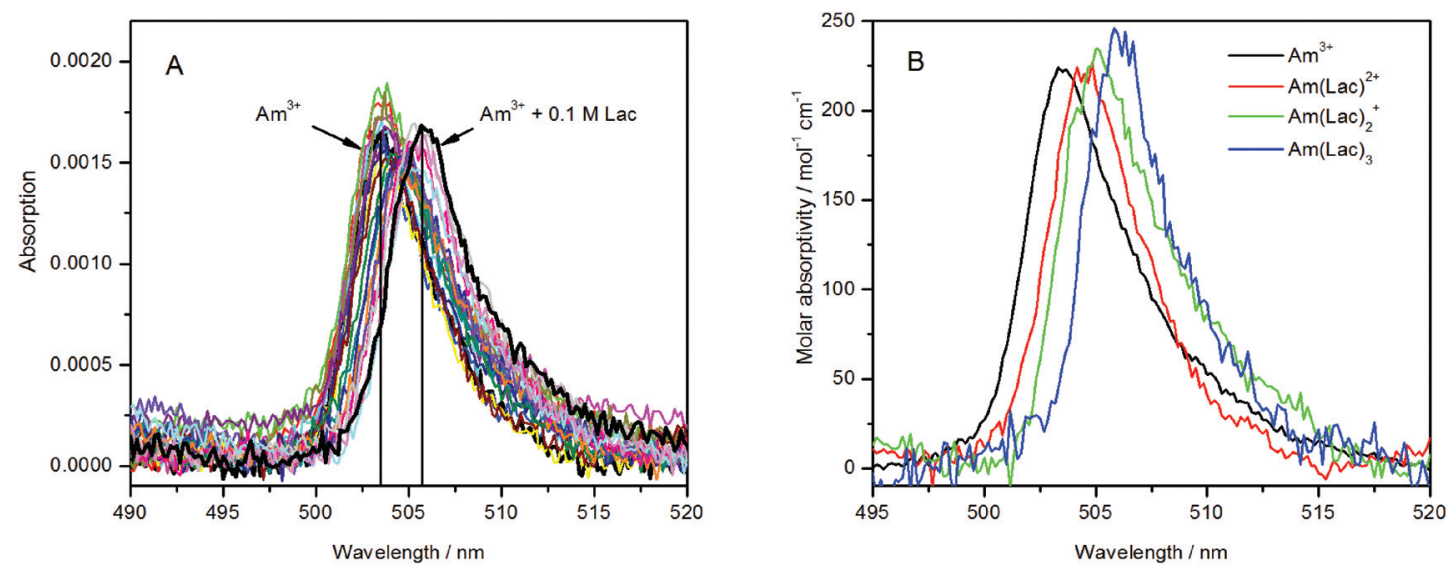

Fig. 1 Absorption spectra of $5 \mu \mathrm{M} \mathrm{Am}(\mathrm{III})$ in dependence of the lactate concentration $(50 \mu \mathrm{M}$ to $0.1 \mathrm{M}), \mathrm{pH}=6.0, I=0.1 \mathrm{M}, T=25^{\circ} \mathrm{C}$ (left), deconvoluted spectra of the single species (right). 
The quantitative analysis of the spectra clearly shows the formation of three Am(III) lactate complexes with a lactate concentration up to $0.1 \mathrm{M}, \mathrm{Am}(\mathrm{Lac})^{2+}, \mathrm{Am}(\mathrm{Lac})_{2}{ }^{+}$and $\mathrm{Am}(\mathrm{Lac})_{3}$, as it was expected from literature. ${ }^{3,13}$ Fig. 1B shows the deconvoluted single spectra of each individual species. They are very similar to those recently determined in trifluoromethansulfonate media. ${ }^{13}$ The simultaneous determination of all three complex formation constants results in relatively large uncertainties. Only for the 1:1 complex, the quality could be increased by using only the spectra up to a lactate concentration of $0.01 \mathrm{M}$. In this concentration range the $1: 1$ complex should be the dominating species. The complex formation constant was determined to be $\log \beta_{11}=2.22 \pm 0.11$, providing that only the carboxylic group of lactate is deprotonated. This is in accordance with literature e $^{3,10,13,15}$ (see Table 1). The quality of the formation constants of the $1: 2$ and $1: 3$ complexes, respectively, could not be increased properly; possibly the spectral changes are too small to get more precise results than $\log \beta_{12}=4.5 \pm 0.3$ for $\mathrm{Am}(\mathrm{Lac})_{2}{ }^{+}$, and $\log \beta_{13}=6.3 \pm 0.3$

Table 1 Conditional complex stability constants log $\beta_{\mathrm{ML}(\mathrm{H})}$ of $\mathrm{Am}(\mathrm{II})$ lactate complexes at $I=0.1 \mathrm{M}\left(\mathrm{NaClO}_{4}\right)$ and varying temperatures determined in this work ( $\mathrm{pH}=3.0-6.0)$ in comparison with literature data. Values at $I=0$ were calculated from present work's values applying SIT

\begin{tabular}{llllll}
\hline & & $\begin{array}{c}\mathrm{Am}(\mathrm{Lac})^{2+} \\
\log \beta_{11(1)} \mathrm{C}\end{array}$ & $\begin{array}{c}\mathrm{Am}(\mathrm{Lac})_{2}{ }^{+} \\
\log \beta_{12(2)}\end{array}$ & $\begin{array}{l}\mathrm{Am}(\mathrm{Lac})_{3} \\
\log \beta_{13(3)}\end{array}$ & $\begin{array}{l}\text { Ref. } \\
\text { Method }\end{array}$ \\
\hline 10 & 1.5 & 2.57 & 4.21 & & $10^{a}$ \\
25 & 2 & $2.52 \pm 0.04$ & $4.77 \pm 0.05$ & $5.98 \pm 0.08$ & $15^{b}$ \\
& 1 & $2.43 \pm 0.09$ & $4.23 \pm 0.27$ & $5.65 \pm 0.15$ & $3^{b}$ \\
& $1(\mathrm{NaTf})$ & $2.60 \pm 0.06$ & $4.7 \pm 0.1$ & $6.2 \pm 0.2$ & $13^{c}$ \\
& 0.1 & $2.27 \pm 0.05$ & $4.5 \pm 0.3$ & $6.3 \pm 0.3$ & p.w. ${ }^{c}$ \\
& 0.1 & $2.22 \pm 0.11$ & & & p.w. ${ }^{d}$ \\
45 & 0 & $2.87 \pm 0.26$ & $5.5 \pm 0.4$ & $7.5 \pm 0.4$ & p.w. \\
& 0.1 & $2.17 \pm 0.19$ & & & p.w. ${ }^{d}$ \\
65 & 0.1 & $2.82 \pm 0.31$ & & & p.w. ${ }^{d}$ \\
& 0 & $2.35 \pm 0.31$ & & & p.w. ${ }^{d}$ \\
& & $3.03 \pm 0.39$ & & & p.w.
\end{tabular}

$\log \beta_{\mathrm{ML}(\mathrm{H})}$ are the stability constants with protonated hydroxyl group(s), not considering the $\mathrm{p} K_{\mathrm{a} 2}$ of lactic acid. ${ }^{a}$ Electrophoresis. ${ }^{b}$ Solvent extraction. ${ }^{c}$ UV-vis. ${ }^{d}$ TRLFS. NaTf $=$ Na-trifluoromethansulfonate; p.w. $=$ present work. for $\mathrm{Am}(\mathrm{Lac})_{3}$. Nevertheless, these values are in the range of published data ${ }^{3,10,13,15}$ (see Table 1).

\section{Am(III) time-resolved laser-induced fluorescence spectroscopy}

The best excitation wavelength for luminescence emission corresponds to the absorption maximum of the luminescent species. The highest luminescence intensity for the Am(III) aqua ion can be observed at 503-504 nm excitation (Fig. 2A), whereas the best excitation in the presence of $0.1 \mathrm{M}$ lactate is at 506-507 nm (Fig. 2B). For the determination of the complex stability constants, an excitation wavelength of $504 \mathrm{~nm}$ was used, where the luminescence intensity of both the uncomplexed and complexed Am(III) species is satisfactory for quantitative determinations.

The Am(III) aqua ion shows at pH 6.0 and different temperatures a luminescence lifetime of $23.8 \pm 2.4 \mathrm{~ns}\left(25^{\circ} \mathrm{C}\right), 22.8 \pm$ $0.9 \mathrm{~ns}\left(40^{\circ} \mathrm{C}\right)$ or $23.3 \pm 1.5 \mathrm{~ns}\left(65^{\circ} \mathrm{C}\right)$, corresponding to approximately 9 coordinating water molecules. This agrees with previous measurements. ${ }^{18,25}$ Complex formation with lactate causes a strong increase of the luminescence intensity and a red shift of the luminescence maximum of about $5 \mathrm{~nm}$ (Fig. 3, left). The luminescence decay is always mono-exponential, irrespective of the number of expected different Am(III) species (see Fig. S1 and S2, ESI $\dagger$ ). This is caused by an exchange of the Am(III) coordination environments, which is faster than the luminescence decay rate of the excited state and results in a concentration-weighted average number of water molecules of all Am(III) species. ${ }^{52}$ The luminescence lifetime is prolonged up to $38.3 \pm 0.4 \mathrm{~ns}\left(25^{\circ} \mathrm{C}, 0.1 \mathrm{M}\right.$ lactate, $\mathrm{pH}$ 6.0 ). This value corresponds to 5 remaining water molecules, indicating an exchange of 4 water molecules with ligand molecules' coordination sites. It implies the formation of not only a 1:1 complex but also a certain amount of complexes with higher stoichiometry like $1: 2$ or $1: 3$ complexes.

The quantitative deconvolution of the luminescence spectra in order to determine complex stability constants for all three complexes failed. Possibly the spectral changes are too small to discriminate all three complexes. A reasonable stability constant could only be determined for the $1: 1$ complex. For determination of the formation constant of the $1: 1$ complex, the spectra with a lactate concentration up to $0.01 \mathrm{M}$ were con-
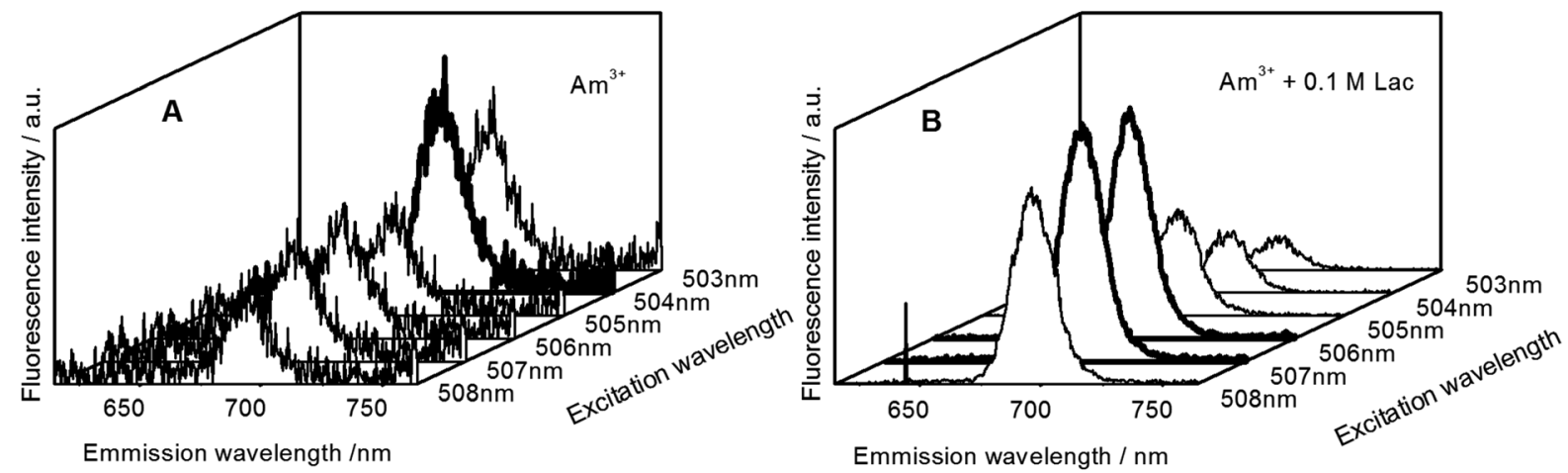

Fig. 2 Emission spectra of (A) $5 \mu \mathrm{M} \mathrm{Am}$ (III) and (B) $5 \mu \mathrm{M} \mathrm{Am}(\mathrm{III})+0.1 \mathrm{M}$ lactate in dependence of the excitation wavelength. 

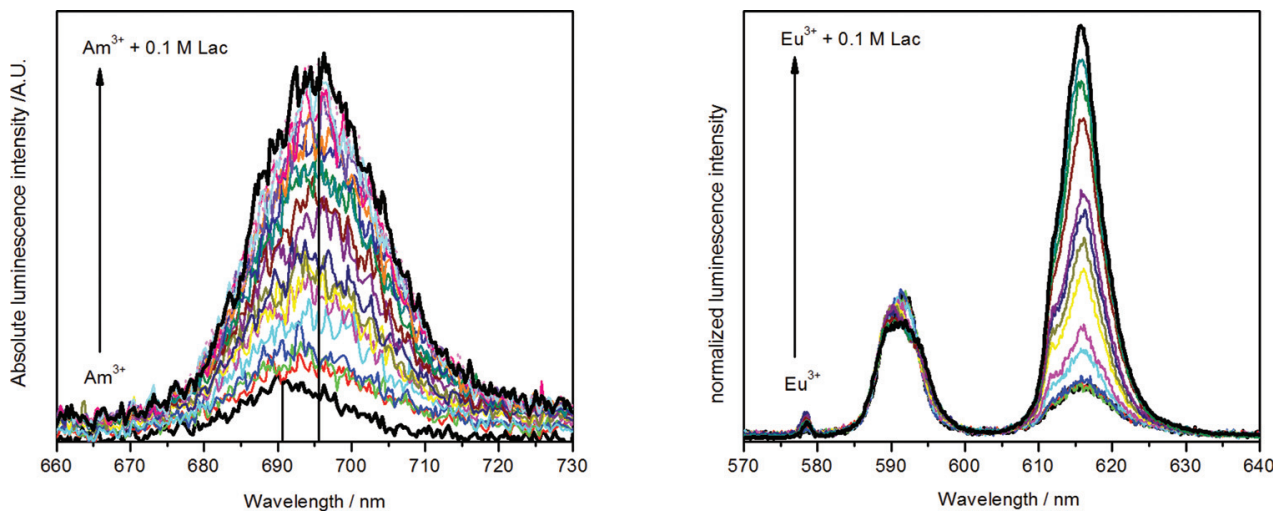

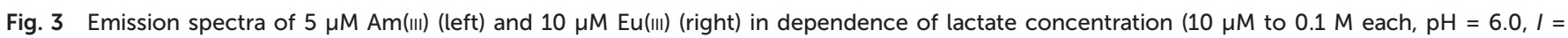
$0.1 \mathrm{M}, T=25^{\circ} \mathrm{C}$ ).

sidered in analogy to the UV-vis measurements, yielding a log $\beta_{11}=2.27 \pm 0.05\left(25^{\circ} \mathrm{C}\right)$. This is in very good accordance to the value from UV-vis spectroscopy and to literature values (see Table 1).

TRLFS measurements were also done at elevated temperatures $\left(45^{\circ} \mathrm{C}\right.$ and $\left.65{ }^{\circ} \mathrm{C}\right)$. The stability constant of the $1: 1$ complex shows no relevant tendency with rising temperature, indicating that the complex formation reaction causes only a very small enthalpy change. The van't Hoff plot (see Fig. 4) results in an enthalpy change closed to zero within the error bars (see Table 3). Other studies calculated a negative reaction enthalpy, corresponding to an exothermic reaction ${ }^{3,13}$ (Table 3). This discrepancy is possibly due to different ionic strengths and ionic media. A detailed discussion to this effect is provided in the next section.

\section{Eu(III) time-resolved laser-induced fluorescence spectroscopy}

The complex formation of $\mathrm{Eu}(\mathrm{III})$ with lactate was studied with TRLFS at near neutral $\mathrm{pH}(3.0-6.0)$ and ambient to higher temperature $\left(25-70{ }^{\circ} \mathrm{C}\right)$. Because of the high importance of

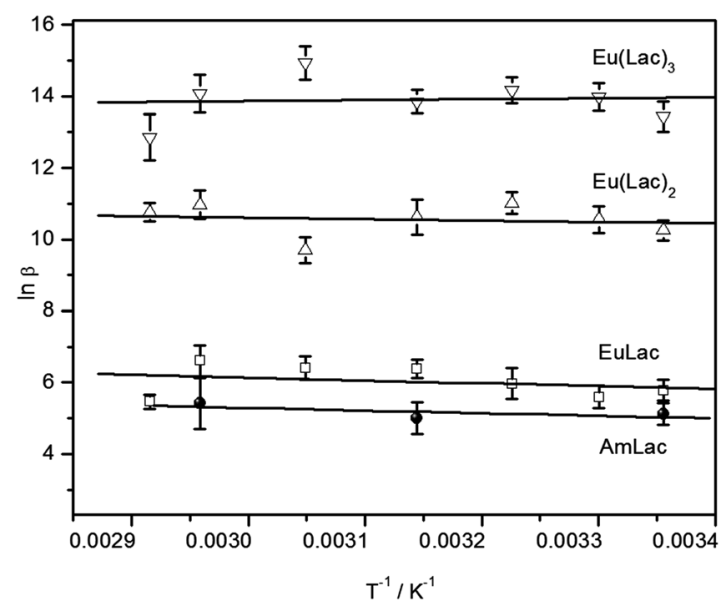

Fig. 4 Van't Hoff plots of the Am(III) lactate and Eu(III) lactate complex formation. lactate in metabolism the biological relevant temperature of $37^{\circ} \mathrm{C}$ was included. The luminescence spectra in dependence of the lactate concentration are depicted in Fig. 3 (right). During ligand addition, the characteristic changes in Eu(III) luminescence spectrum caused by complex formation can be observed: a strong increase of the hypersensitive ${ }^{5} \mathrm{D}_{0} \rightarrow{ }^{7} \mathrm{~F}_{2}$ transition at about $615 \mathrm{~nm}$ and the appearance of the symmetry forbidden ${ }^{5} \mathrm{D}_{0} \rightarrow{ }^{7} \mathrm{~F}_{0}$ transition at around $578 \mathrm{~nm}$ (see Fig. 3, right). The luminescence lifetime is prolonged from $111.5 \pm$ $2.2 \mu \mathrm{s}\left(25{ }^{\circ} \mathrm{C}\right)$ for the $\mathrm{Eu}$ (III) aqua ion up to $223.9 \pm 1.3 \mu \mathrm{s}$ $\left(25{ }^{\circ} \mathrm{C}, 0.1 \mathrm{M}\right.$ lactate, $\mathrm{pH}$ 6.0). The former corresponds to 9 water molecules in the first hydration shell of the $\mathrm{Eu}(\mathrm{III})$ aqua ion and is in accordance with literature. ${ }^{53,54}$ As it was observed for $\mathrm{Am}(\mathrm{III})$, also the $\mathrm{Eu}$ (III) lactate system shows always monoexponential decay due to a fast ligand exchange in the first coordination sphere (see Fig. S3 and S4, ESI†̈). The resultant concentration-weighted average lifetime consists of certain contributions of the expected species. Upon complex formation with lactate, the average number of water molecules is reduced to $4.2 \pm 0.5$ at the highest lactate concentration $(0.1 \mathrm{M})$. This indicates the formation of complexes with different metal-to-ligand ratios, possibly $1: 1,1: 2$ and $1: 3 \mathrm{com}$ plexes as it was suggested for the lactate complex formation with Am(III) and already described in previous studies. ${ }^{4,6,7,9}$

Complex stability constants were determined for all three complexes and various temperatures between $25^{\circ} \mathrm{C}$ and $70{ }^{\circ} \mathrm{C}$, provided that only the carboxylic group of lactate is deprotonated (see Table 2). The stability constants show no significant trend with rising temperature, however, the van't Hoff plot (Fig. 4) results in a small positive reaction enthalpy change for the $1: 1$ and $1: 2$ complexes and a very small negative reaction enthalpy for the $1: 3$ complex (see Table 3), equivalent to an endothermic reaction for the former and an exothermic reaction for the latter complex. Previous investigations from Tian ${ }^{4}$ gave small negative reaction enthalpy changes for all three complexes. However, these measurements were done at an ionic strength of $1 \mathrm{M}$. The reaction enthalpies determined from $\mathrm{Aziz}^{7}$ and Choppin ${ }^{6}$ at an ionic strength of $2 \mathrm{M}$ are even more negative (see Table 3). This gives the following ionic 
Table 2 Conditional complex stability constants log $\beta_{\mathrm{ML}(\mathrm{H})}$ of $\mathrm{Eu}(\mathrm{III})$ lactate complexes at $I=0.1 \mathrm{M}\left(\mathrm{NaClO}_{4}\right)$ and varying temperatures determined in this work $(\mathrm{pH}=3.0-6.0)$ in comparison with literature data. Values at $I=0$ were calculated from present work's values applying SIT

\begin{tabular}{|c|c|c|c|c|c|}
\hline$T /{ }^{\circ} \mathrm{C}$ & $I / \mathrm{M}\left(\mathrm{NaClO}_{4}\right)$ & $\begin{array}{l}\mathrm{Eu}(\mathrm{Lac})^{2+} \\
\log \beta_{11(1)}\end{array}$ & $\begin{array}{l}\mathrm{Eu}(\mathrm{Lac})_{2}{ }^{+} \\
\log \beta_{12(2)}\end{array}$ & $\begin{array}{l}\mathrm{Eu}(\mathrm{Lac})_{3} \\
\log \beta_{13(3)}\end{array}$ & $\begin{array}{l}\text { Ref. } \\
\text { Method }\end{array}$ \\
\hline \multirow[t]{3}{*}{10} & 1.5 & 2.62 & 4.22 & & $10^{a}$ \\
\hline & 1.0 & $2.90 \pm 0.36$ & $4.90 \pm 0.37$ & $6.24 \pm 0.30$ & $4^{b}$ \\
\hline & 1.0 & $2.91 \pm 0.24$ & $5.02 \pm 0.22$ & $6.03 \pm 0.28$ & $4^{c}$ \\
\hline \multirow[t]{8}{*}{25} & 2.0 & 2.53 & 4.60 & 5.88 & $9^{b}$ \\
\hline & 1.0 & $2.80 \pm 0.02$ & $4.76 \pm 0.02$ & $6.33 \pm 0.02$ & $4^{b}$ \\
\hline & 1.0 & $2.99 \pm 0.17$ & $5.09 \pm 0.23$ & $6.09 \pm 0.27$ & $4^{c}$ \\
\hline & 1.0 & $2.46 \pm 0.09$ & $4.28 \pm 0.25$ & $5.87 \pm 0.10$ & $3^{d}$ \\
\hline & $1.0(\mathrm{NaCl})$ & 2.95 & 4.40 & 5.47 & $11^{d}$ \\
\hline & 0.2 & $2.55 \pm 0.05$ & $4.67 \pm 0.06$ & $5.55 \pm 0.18$ & $8^{b}$ \\
\hline & 0.1 & $2.51 \pm 0.13$ & $4.45 \pm 0.12$ & $5.83 \pm 0.18$ & p.w. ${ }^{c}$ \\
\hline & 0 & $3.14 \pm 0.28$ & $5.49 \pm 0.28$ & $7.07 \pm 0.31$ & p.w. \\
\hline \multirow[t]{2}{*}{30} & 0.1 & $2.43 \pm 0.14$ & $4.58 \pm 0.16$ & $6.07 \pm 0.17$ & p.w. ${ }^{c}$ \\
\hline & 0 & $3.06 \pm 0.29$ & $5.63 \pm 0.30$ & $7.32 \pm 0.30$ & p.w. \\
\hline \multirow[t]{2}{*}{37} & 0.1 & $2.59 \pm 0.19$ & $4.78 \pm 0.13$ & $6.15 \pm 0.16$ & p.w. ${ }^{c}$ \\
\hline & 0 & $3.24 \pm 0.31$ & $5.85 \pm 0.28$ & $7.42 \pm 0.30$ & p.w. \\
\hline \multirow[t]{2}{*}{40} & 1.0 & $2.78 \pm 0.15$ & $4.57 \pm 0.11$ & $6.25 \pm 0.21$ & $4^{b}$ \\
\hline & 1.0 & $2.91 \pm 0.17$ & $5.04 \pm 0.27$ & $6.17 \pm 0.25$ & $4^{c}$ \\
\hline \multirow[t]{2}{*}{45} & 0.1 & $2.77 \pm 0.11$ & $4.61 \pm 0.21$ & $6.01 \pm 0.14$ & p.w. ${ }^{c}$ \\
\hline & 0 & $3.42 \pm 0.27$ & $5.69 \pm 0.33$ & $7.30 \pm 0.29$ & p.w. \\
\hline \multirow[t]{4}{*}{55} & 1.0 & $2.70 \pm 0.11$ & $4.43 \pm 0.15$ & $6.28 \pm 0.11$ & $4^{b}$ \\
\hline & 1.0 & $3.04 \pm 0.24$ & $5.00 \pm 0.27$ & $5.95 \pm 0.26$ & $4^{c}$ \\
\hline & 0.1 & $2.78 \pm 0.14$ & $4.21 \pm 0.16$ & $6.48 \pm 0.20$ & p.w. ${ }^{c}$ \\
\hline & 0 & $3.45 \pm 0.29$ & $5.32 \pm 0.30$ & $7.79 \pm 0.32$ & p.w. \\
\hline \multirow[t]{2}{*}{65} & 0.1 & $2.87 \pm 0.19$ & $4.76 \pm 0.17$ & $6.11 \pm 0.23$ & p.w. ${ }^{c}$ \\
\hline & 0 & $3.55 \pm 0.31$ & $5.89 \pm 0.30$ & $7.46 \pm 0.34$ & p.w. \\
\hline \multirow[t]{4}{*}{70} & 1.0 & $2.81 \pm 0.19$ & $4.49 \pm 0.21$ & $6.33 \pm 0.20$ & $4^{b}$ \\
\hline & 1.0 & $2.99 \pm 0.23$ & $4.88 \pm 0.25$ & $5.98 \pm 0.26$ & $4^{c}$ \\
\hline & 0.1 & $2.37 \pm 0.09$ & $4.67 \pm 0.11$ & $5.58 \pm 0.28$ & p.w. ${ }^{c}$ \\
\hline & 0 & $3.06 \pm 0.27$ & $5.82 \pm 0.27$ & $6.94 \pm 0.38$ & p.w. \\
\hline
\end{tabular}

$\log \beta_{\mathrm{ML}(\mathrm{H})}$ are the stability constants with protonated hydroxyl group(s), not considering the $\mathrm{p} K_{\mathrm{a} 2}$ of lactic acid. ${ }^{a}$ Electrophoresis. ${ }^{b}$ Potentiometry. ${ }^{c}$ TRLFS. ${ }^{d}$ Solvent extraction. p.w. $=$ present work. strength dependency of the reaction enthalpy: the higher the ionic strength the lower the reaction enthalpy. A comparison of literature data in data collections has shown a decrease of reaction enthalpy with increasing ionic strength for several metal-ligand systems; even changes from positive to negative enthalpy can be observed. ${ }^{55}$ This is caused by the ionic strength dependent variation in the activity coefficients of the reagents. ${ }^{56}$ In general, two contrary effects contribute to the reaction enthalpy: (1) the partially dehydration of the reactants which is usually endothermic, and (2) the complex formation which is expected to be exothermic. ${ }^{57}$ At low ionic strength the solvation spheres are tightly bound, equivalent to lowering the activity coefficients of the ions. This results in a larger endothermic dehydration enthalpy and the effect (1) mainly contributes to the reaction enthalpy. With higher ionic strength the solvation spheres loosen up because of a higher amount of competition ions. This causes increased activity coefficients of the ions and a smaller endothermic dehydration enthalpy term. In consequence, the contribution of the effect (2) might become dominant and even cause a change of sign of the reaction enthalpy. ${ }^{58}$

It is worth mentioning that the entropy changes are quite high (see Table 3), so we can assume that the complex formation reaction is predominantly entropy driven. The number of water molecules in the first coordination shell of $\mathrm{Eu}$ (III) (deduced from the luminescence lifetimes) helps to explain this. As written earlier, up to 5 water molecules are replaced by 3 ligand molecules which increases the entropy in the system.

The challenge is to receive information about the coordination type of $\mathrm{Eu}(\mathrm{III})$ lactate. Possible structures for the 1:1 complex are depicted in Fig. 5. Is it monodentate coordination of the carboxylate group with a high sterical requirement of the lactate (A) or bidentate coordination with carboxylate and

Table 3 Conditional thermodynamic data of Am(III) and Eu(III) lactate complexes determined spectrophotometrically (TRLFS) in this work in comparison with literature data

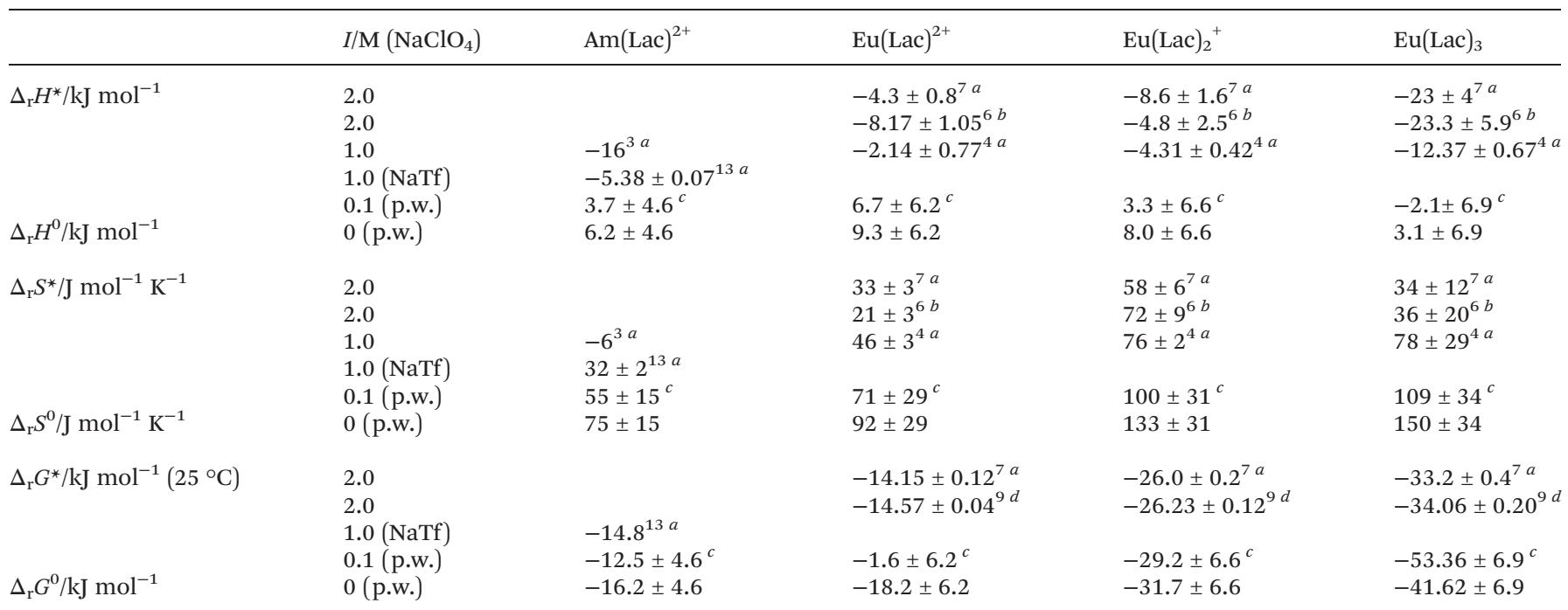

${ }^{a}$ Solvent extraction. ${ }^{b}$ Calorimetry. ${ }^{c}$ TRLFS. ${ }^{d}$ Potentiometry. NaTf $=$ Na-trifluoromethansulfonate; p.w. $=$ present work. 
<smiles>CCOC(=O)C(C)O</smiles>

A<smiles>CC1OC(=O)C(O)O1</smiles>

B<smiles>CC1OC(=O)C(=O)O1</smiles>

C<smiles>CC(O)C1OC(O)O1</smiles>

D

Fig. 5 Possible structures of the Eu(III) lactate 1:1 complex: (A) monodentate, (B) bidentate with coordinating hydroxyl group, (C) bidentate with deprotonated hydroxyl group, (D) bidentate binding of the carboxylate group.

hydroxyl group, protonated (B) or deprotonated (C) or bidentate coordination of the carboxylate group (D)? Spectroscopic (FT-IR, NMR) and computational (DFT) techniques were carried out to get an idea about the coordination behavior of the Eu(III) lactate $1: 1$ complex.

\section{Vibrational spectroscopy and DFT analysis}

Lactate. Infrared measurements in combination with DFT calculations open the possibility to assign the absorption bands exactly to the respective vibrational modes of the molecule. Prior to the measurement of the $\mathrm{Eu}(\mathrm{III})$ lactate complex, the vibrational spectrum of the pure ligand at $\mathrm{pH} 5$ was measured and calculated (Fig. S5, ESI $\dagger$ ). The calculation was done for the lactate molecule in aqueous solution with deprotonated carboxylate group, protonated hydroxyl group and 7 water molecules (Fig. S6, ESI $\dagger$ ). The measured IR spectrum (Fig. 6a) shows the typical asymmetric and symmetric stretching vibrations $\nu_{\text {as }}$ and $\nu_{\mathrm{s}}$ of the deprotonated carboxylate group at 1575 and $1416 \mathrm{~cm}^{-1}$, respectively, and the stretching vibration $\nu$ of the protonated hydroxyl group is to be found at $1127 \mathrm{~cm}^{-1}$. The assignment could be verified by the calculated IR spectrum (see Fig. S5, ESI $\dagger$ ). On the basis of the calculated spectrum the absorption modes at 1455 and $1365 \mathrm{~cm}^{-1}$ could be assigned to bending vibrations of the methyl group, and that at $1040 \mathrm{~cm}^{-1}$ to the stretching vibration of $\mathrm{C}-\mathrm{C}\left(\mathrm{C}-\mathrm{CH}_{3}\right)$.

Eu(III) lactate. The ATR FT-IR spectrum of the Eu(III) lactate $1: 1$ complex (Fig. 6b) shows in principle the same vibration

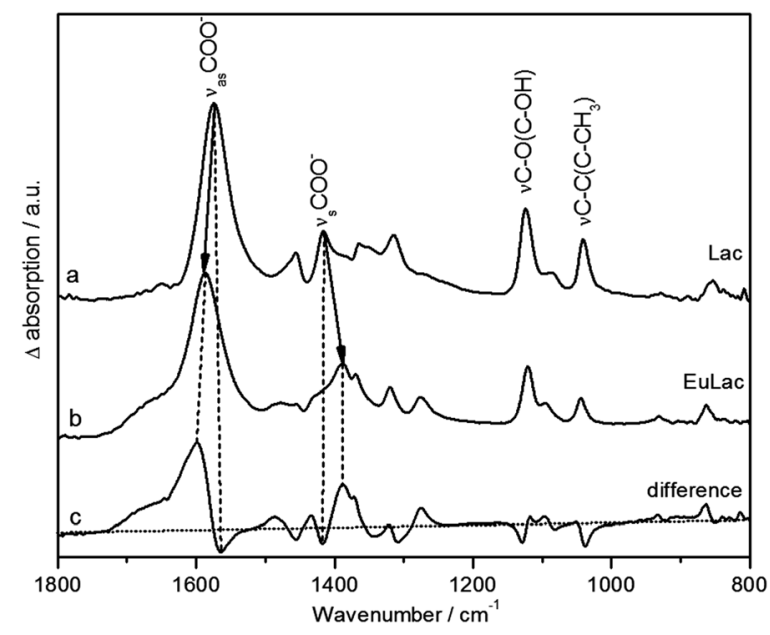

Fig. 6 Experimental infrared spectra of lactate at pH 5 (a), Eu(III) lactate at $\mathrm{pH} 5$ (b), and the calculated difference spectrum Eu(II) lactate minus lactate (c). modes as the pure ligand (Fig. 6a). The difference spectrum (Fig. 6c) shows the shifts of the modes more clearly; hereby positive peaks represent vibrational modes of the $\mathrm{Eu}(\mathrm{III})$ lactate complex and negative peaks those of the pure ligand. Upon complex formation, the asymmetric and symmetric stretching vibrations $\nu_{\text {as }}$ and $\nu_{\mathrm{s}}$ of the carboxylate group are shifted to higher $\left(\nu_{\mathrm{as}}, 1588 \mathrm{~cm}^{-1}\right)$ and lower $\left(\nu_{\mathrm{s}}, 1388 \mathrm{~cm}^{-1}\right)$ frequencies,

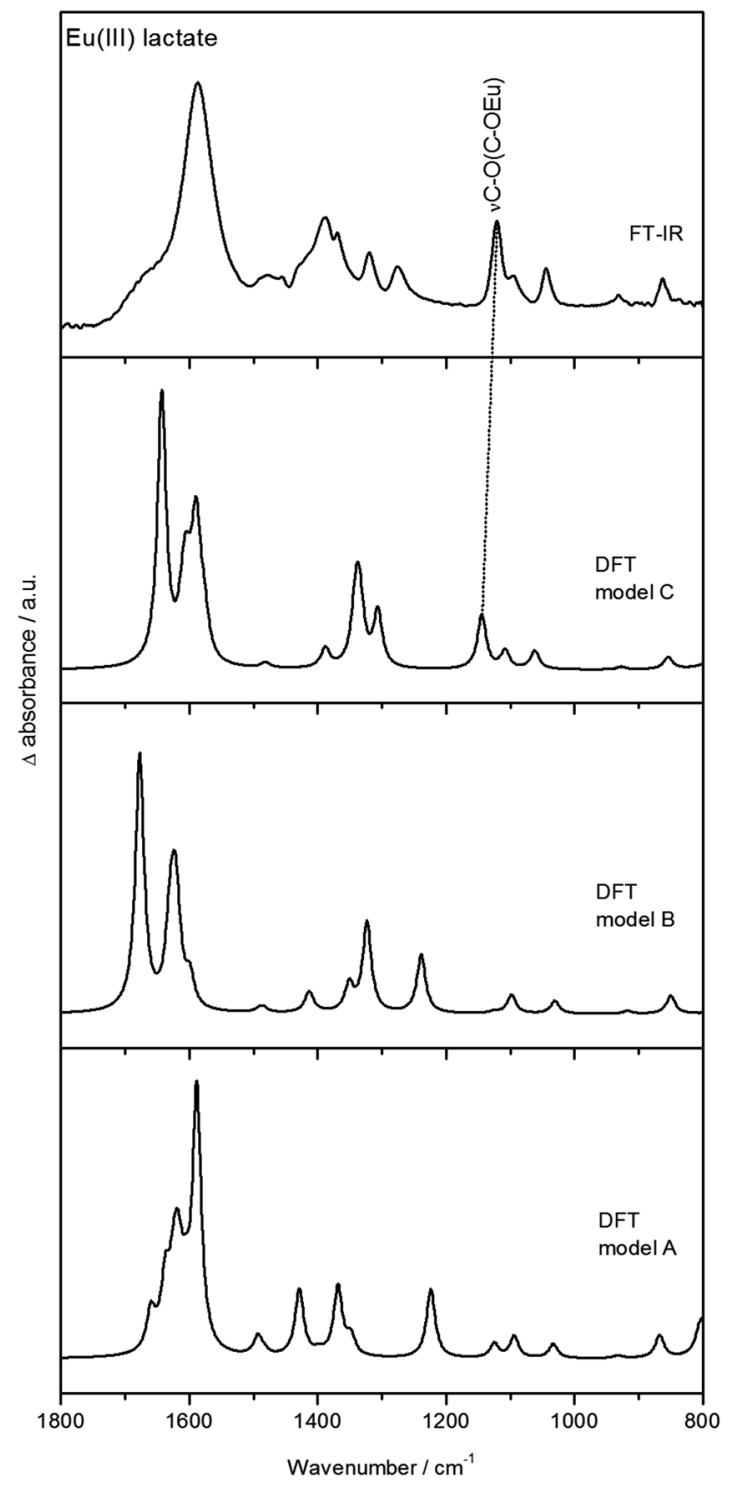

Fig. 7 Experimental (ATR FT-IR) and calculated (DFT) spectra of Eu(III) lactate. Calculations were done for structures A, B, and C (from Fig. 5). 
respectively. By the degree of spectral splitting of the $\nu_{\mathrm{s} / \text { as }}(\mathrm{COO})(\Delta \nu)$ the type of coordination of the carboxylate group can be derived. The $\Delta \nu$ value of the uncomplexed ligand serves as reference; in our case it is $159 \mathrm{~cm}^{-1}$. In general, bidentate coordination is expected to show a significantly lower spectral splitting, whereas monodentate coordination usually exhibits a larger splitting compared to the uncomplexed ligand. ${ }^{59,60}$ The Eu(III) lactate $1: 1$ complex shows a $\Delta \nu$ of $200 \mathrm{~cm}^{-1}$, which is a strong indication for monodentate carboxylate coordination. So we can rule out structure D (Fig. 5) with bidentate coordination mode of the carboxylate group.

The difference spectrum (Fig. 6c) shows additionally significant changes of the spectral modes at around $1120 \mathrm{~cm}^{-1}$ and $1040 \mathrm{~cm}^{-1}$ (strong negative bands in the difference spectrum). According to DFT calculations (see Fig. 7 and Fig. S7, ESI $\dagger$ ), these modes can be assigned to the $\mathrm{C}-\mathrm{O}$ stretching vibration of the hydroxyl group and the subsequent $\mathrm{C}-\mathrm{C}$ stretching vibration of the $\mathrm{C}-\mathrm{CH}_{3}$ unit, respectively.

Fig. 7 shows the DFT calculated vibrational spectra for the models A, B, and $\mathrm{C}$ from Fig. 5 in comparison with the measured ATR FT-IR spectrum of Eu(III) lactate. The best accordance to the measured spectrum is given by model C. Especially the peak at around $1120 \mathrm{~cm}^{-1}$ (measured spectrum) finds its equivalent only in the calculated IR spectrum of model C $\left(1145 \mathrm{~cm}^{-1}\right)$. In the calculated IR spectra of models $\mathrm{A}$ and $\mathrm{B}$, this peak is missing or shifted strongly to $1224 \mathrm{~cm}^{-1}$ (model A) and $1238 \mathrm{~cm}^{-1}$ (model $\mathrm{B}$ ), respectively. This mode is caused by the $\mathrm{C}-\mathrm{O}$ stretching vibration of the hydroxo group which is protonated in models A and B. In model $\mathrm{C}$ this functionality is deprotonated resulting in a covalent binding to the $\mathrm{Eu}(\mathrm{III})$ cation. Due to the position of this stretching vibration mode in the measured spectrum compared to the calculated spectra it is assumed that model $\mathrm{C}$ reflects best the binding behavior of the Eu(III) lactate complex. The coordinating hydroxyl group seems to become deprotonated under complex formation with $\mathrm{Eu}(\mathrm{III})$.

\section{NMR spectroscopy}

${ }^{1}$ H-NMR. The ${ }^{1} \mathrm{H}$-NMR spectra (Fig. 8) show the interaction between lactate and $\mathrm{Eu}(\mathrm{III})$. They contain two signals each of which are split due to $J(\mathrm{H}, \mathrm{H})$-coupling; the quartet represents the $\mathrm{CH}$ and the doublet the $\mathrm{CH}_{3}$ protons, respectively. The signal areas stand for the relative proton number, i.e. the $\mathrm{CH}_{3}$ signal (doublet) has threefold area compared to the $\mathrm{CH}$ signal (quartet). The paramagnetic center causes considerable shifts as well as very efficient relaxation of the protons. This results in a reduced splitting of the $\mathrm{CH}$ and the $\mathrm{CH}_{3}$ signals with increasing amounts of the metal. $J$-couplings can only be observed if the coupled nuclei do not change their magnetic orientation within the reciprocal coupling constant (expressed in terms of time). With decreasing relaxation time the remaining time between excitation and relaxation limits the build-up in coupling. Furthermore, the lines are broadened as a consequence of fast relaxation as well as exchange processes.

${ }^{13} \mathrm{C}-\mathrm{NMR}$. The ${ }^{13} \mathrm{C}-\mathrm{NMR}$ spectra and their graphical evaluation in Fig. 9 and 10, respectively, show chemical shift $(\delta)$ dependence on the ligand to metal ratio. In this experiment, the lactate concentration was $0.1 \mathrm{M}$ whereas that of $\mathrm{Eu}(\mathrm{III})$ was varied (Fig. 9C-F). As a consequence of fast exchange between free and bound ligand, the chemical shift of the apparent signal is the sum of the chemical shifts of free and bound ligand, respectively, weighted with their individual molar frac-

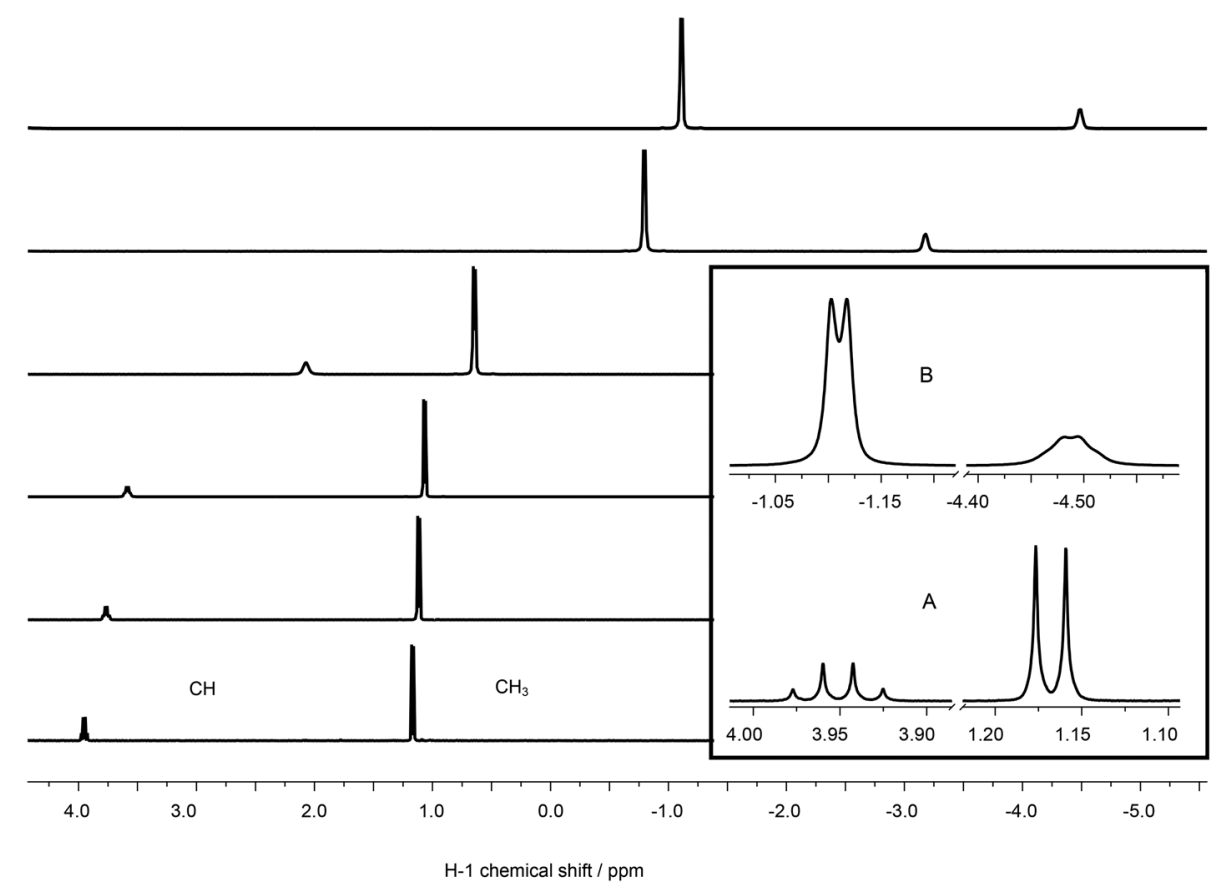

Fig. $8{ }^{1} \mathrm{H}$-NMR spectra of $0.1 \mathrm{M}$ lactate with varying Eu(III) concentration (from bottom to top: 0, 1, 5, 10, 50, $100 \mathrm{mM}$ ). The inset shows expansions of lactate samples without Eu (A) and with equimolar concentration of Eu (B). 


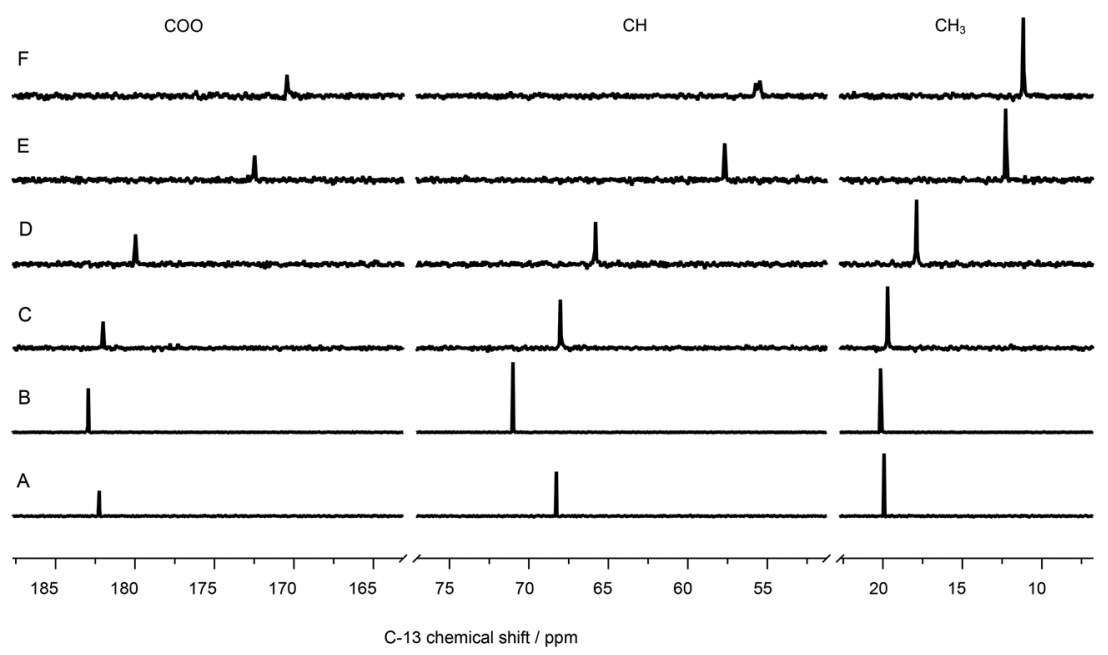

Fig. $9{ }^{13}$ C-NMR spectra of $100 \mathrm{mM}$ lactate, (A) without metal, (B) containing $120 \mathrm{mM} \mathrm{La(III),} \mathrm{and} \mathrm{(C)} \mathrm{5,} \mathrm{(D)} \mathrm{10,} \mathrm{(E)} \mathrm{50,} \mathrm{(F)} \mathrm{100} \mathrm{mM} \mathrm{Eu(III).}$

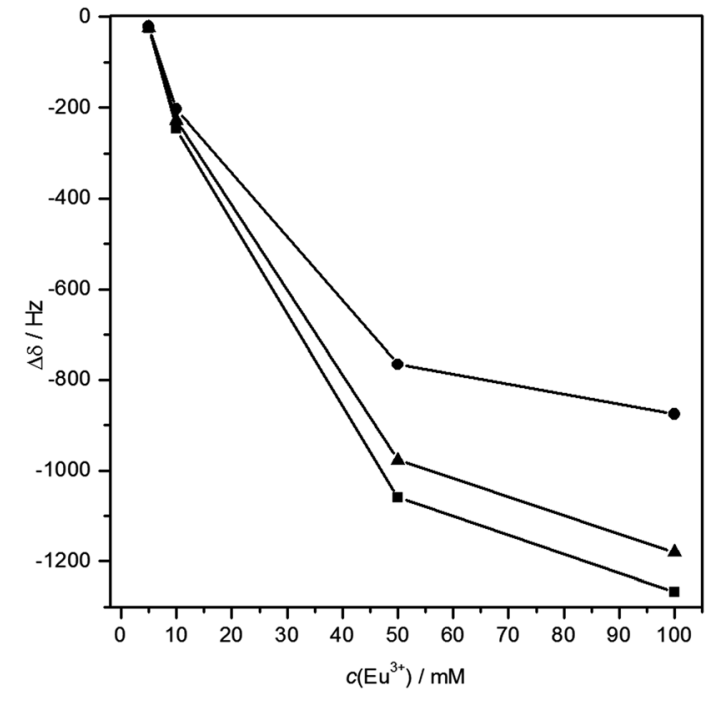

Fig. 10 Plot of ${ }^{13} \mathrm{C}$ chemical shift differences vs. Eu(III) concentration. $\mathbf{a C H}, \mathbf{\Delta C O O}, \bullet \mathrm{CH}_{3}$, lines drawn for better visualization.

tion. Therefore, the magnitude of the shift increases with decreasing excess of free ligand, with concomitant increase in complex concentration. With increasing $\mathrm{Eu}(\mathrm{III})$ concentration the individual signals are shifted differently. Since the lanthanide induced shift (LIS) of the europium's unpaired f-electrons ( $4 \mathrm{f}^{6}$ configuration) on the carbon nuclei is distance dependent, the shift differences $(\Delta \delta)$ are a qualitative measure of $\mathrm{C}-\mathrm{Eu}$ distances. Both the carboxylic and the $\mathrm{OH}$ bearing carbon have similar $\Delta \delta$ indicating similar europium distances. Because of the bigger Eu(III) distance the methyl carbon is less affected (see Fig. 10).

Using $\mathrm{La}(\mathrm{III})\left(4 \mathrm{f}^{0}\right.$ configuration, closed shell) as a diamagnetic analogue of $\mathrm{Eu}(\mathrm{III})$, the chemical shift changes induced by interaction of the unpaired f-electrons (LIS) can be separated from the pure charge and complex formation induced shifts. As expected, the positive charge of the trivalent metal ion causes a de-shielding, i.e. reduction of electron density of the nuclei at or near the binding site, $c f$. Fig. 9B. Therefore, the carbon signals are shifted to higher chemical shift values. Interestingly, also in this case the $\mathrm{CH}$ carbon is affected most, pointing towards a strong participation of the hydroxyl oxygen in the complex formation. In the case of Eu(III), magnitude and direction of the shift are related to the distribution of f-electron-density at the nuclei of interest, overcompensating the pure charge induced effects.

The LIS has two contributions: (1) contact term, i.e., interaction via bonds and (2) pseudo-contact term, i.e., through space. The contact term depends on type and number of bonds between the (open shell) metal center and the atom of interest. The pseudo-contact term is mediated through dipolar interaction and strongly distance dependent. Both terms can contribute to different extent, depending on, e.g., the electronic configuration and the energy of the ground state or the ligand field splitting. ${ }^{61}$ Neither for ${ }^{1} \mathrm{H}$ nor for ${ }^{13} \mathrm{C}$ do the shifts of signals of adjacent atoms show alternating signs, indicating that the contact contribution can be neglected. ${ }^{62}$ Thus, the observed differences in LIS can be fully attributed to spatial europium distances.

Interestingly, the $\mathrm{CH}$ carbon atom shows the strongest LIS, indicating that this carbon is affected mostly by the europium's unpaired electrons. This can be explained only by participation of the hydroxyl oxygen in $\mathrm{Eu}(\mathrm{III})$ coordination. Therefore, model A (Fig. 5) can be excluded.

Model B (Fig. 5) contains the coordination by the hydroxyl oxygen, but being protonated. Due to this hydrogen, the distance between Eu(III) and this particular oxygen as well as the adjacent carbon is bigger than for both the carboxylic oxygen and carbon (distances calculated with DFT, see Fig. S7, ESI $\dagger$ ). This is in contradiction to the ${ }^{13} \mathrm{C}-\mathrm{NMR}$ results.

Model C (Fig. 5), however, reflects perfectly the NMR findings: same distance between the carbons of interest and Eu(III) (3.24 A, calculated with DFT, $c f$. Fig. S7, ESI $\dagger$ ), resulting in similar magnitude of LIS. The small discrepancy in the chemical shift differences of these two particular carbons ( $c f$. Fig. 10) 
Table 4 Recalculated complex stability constants $\log \beta_{\mathrm{MLH}}$ and thermodynamic data of $\mathrm{Eu}(\mathrm{Lac})^{2+}$ under consideration of the $\mathrm{p} K_{\mathrm{a} 2}(\mathrm{OH})$ of lactate at $I=0.1 \mathrm{M}\left(\mathrm{NaClO}_{4}\right)$ and varying temperatures determined in this work $(\mathrm{pH}=6)$. Values at $I=0$ were calculated applying SIT

\begin{tabular}{lll}
\hline$T /{ }^{\circ} \mathrm{C}$ & $\log \beta^{*}{ }_{110}$ & $\log \beta^{\circ}{ }_{110}{ }^{a}$ \\
\hline 25 & $7.52 \pm 0.07$ & 8.80 \\
30 & $7.28 \pm 0.07$ & 8.57 \\
37 & $7.33 \pm 0.06$ & 8.64 \\
45 & $7.66 \pm 0.04$ & 8.99 \\
55 & $7.73 \pm 0.05$ & 9.08 \\
65 & $7.53 \pm 0.05$ & 8.92 \\
70 & $7.23 \pm 0.12$ & 8.63 \\
$\Delta_{\mathrm{r}} H / \mathrm{kJ} \mathrm{mol}^{-1}$ & $7.7 \pm 3.0$ & $12.9 \pm 3.0$ \\
$\Delta_{\mathrm{r}} S / \mathrm{J} \mathrm{mol}{ }^{-1} \mathrm{~K}^{-1}$ & $169 \pm 10$ & $210 \pm 10$ \\
$\Delta_{\mathrm{r}} G / \mathrm{kJ} \mathrm{mol}^{-1}\left(25{ }^{\circ} \mathrm{C}\right)$ & $-42.7 \pm 3.0$ & $-49.7 \pm 3.0$ \\
${ }^{a}$ Uncertainty \pm 0.25. & & \\
\end{tabular}

is probably related to the angle between the crystal field axis of the complex and the radius vector from $\mathrm{Eu}(\mathrm{III})$ to the respective carbon. The NMR findings strongly support the results obtained from ATR FT-IR measurements in combination with DFT calculations.

With respect to this new findings, the complex formation constants of the $\mathrm{Eu}(\mathrm{III})$ lactate $1: 1$ complex have to be recalculated considering the $\mathrm{p} K_{\mathrm{a}}$ of the hydroxyl group. ${ }^{30}$ The resultant constants and thermodynamic data are listed in Table 4. Interestingly, the recalculation process of the complex formation constants shows that only the 1:1 complex seems to exist with deprotonated hydroxyl group. The calculation of stability constants with further fully deprotonated lactate ligands failed. At $\mathrm{pH} 3$, the hydroxyl group even of the first lactate remains protonated.

\section{Conclusion}

The combination of spectroscopic and theoretical methods for the investigation of the $\mathrm{Am}(\mathrm{III}) / \mathrm{Eu}(\mathrm{III})$ lactate system provides a broad set of information. From UV-vis and TRLFS measurements thermodynamic data were achieved. A negative correlation between ionic strength and reaction enthalpy has been noticed. With higher ionic strength the enthalpies become smaller and the reactions change from endothermic to exothermic. This indicates that with higher temperature the complexes become more stable at lower ionic strengths and weaker at higher ionic strength. On the other hand, at ambient temperature the complexes seem to become stronger with higher ionic strength. Systematic studies to confirm and quantify this assumption are in progress.

The results from ATR FT-IR and NMR measurements combined with DFT calculations provided detailed structural information for the $\mathrm{Eu}(\mathrm{III})$ lactate $1: 1$ complex. The finding that the hydroxyl group seems to be deprotonated under complex formation (model C, Fig. 5) contradicts former structure suggestions, which suppose a coordination of the trivalent metal ion with the protonated hydroxyl group (model B, Fig. 5).,5,12,63
Both experimental methods, ATR FT-IR and NMR, as well as the DFT calculations yielded an impressively homogeneous structural explanation of the investigated $\mathrm{Eu}(\mathrm{III})$ lactate 1:1 species.

The thermodynamic results indicate that the complex formation of trivalent actinides and lanthanides with organic matter is strongly influenced by different parameters like temperature and ionic strength. This makes it difficult to simulate and predict the migration behavior of the metal ions in the environment. Insights in the structural behavior of the complexes in aqueous solution (like it is provided with this study) improve understanding and may result in a more reliable prediction of such migration processes.

\section{Acknowledgements}

This study was partly funded by the German Federal Ministry of Economy (BMWi) under Contract No. 02E11021 and 02 E10417 and the Deutsche Forschungsgemeinschaft (DFG) under Contract No. BE 2234/10-1/2. The authors are grateful for providing of Am-243 from the transplutonium element production facilities at Oak Ridge National Laboratory within collaboration between the Helmholtz-Zentrum Dresden - Rossendorf and Prof. Nitsche from the Lawrence Berkeley National Laboratory. All the quantum chemical calculations were performed using PC-Farm Atlas at the Zentrum für Informationsdienste und Hochleistungsrechnen (ZIH) at the Dresden University of Technology, Germany. The authors thank K. Heim for the ATR FT-IR measurements and M. Zegke for assistance with practical work in the laboratory.

\section{References}

1 L. F. Rao, Chem. Soc. Rev., 2007, 36, 881-892.

2 A. Courdouan, I. Christl, S. Meylan, P. Wersin and R. Kretzschmar, Appl. Geochem., 2007, 22, 2926-2939.

3 R. Lundqvist, J. F. Lu and I. Svantesson, Acta Chem., Scand. Ser. A, 1984, 38, 501-512.

4 G. X. Tian, L. R. Martin and L. F. Rao, Inorg. Chem., 2010, 49, 10598-10605.

5 R. S. Dickins, S. Aime, A. S. Batsanov, A. Beeby, M. Botta, J. Bruce, J. A. K. Howard, C. S. Love, D. Parker, R. D. Peacock and H. Puschmann, J. Am. Chem. Soc., 2002, 124, 12697-12705.

6 G. R. Choppin and H. G. Friedman, Inorg. Chem., 1966, 5, 1599-1603.

7 A. Aziz, S. J. Lyle and J. E. Newbery, J. Inorg. Nucl. Chem., 1971, 33, 1757-1765.

8 H. Deelstra and F. Verbeek, Anal. Chim. Acta, 1964, 31, 251257.

9 G. R. Choppin and J. A. Chopoorian, J. Inorg. Nucl. Chem., 1961, 22, 97-113.

10 M. Sakanoue and M. Nakatani, Bull. Chem. Soc. Jpn., 1972, 45, 3429-3433. 
11 P. R. Danesi, C. Cianetti and E. P. Horwitz, Sep. Sci. Technol., 1982, 17, 507-519.

12 A. P. G. Kieboom, C. A. M. Vijverberg, J. A. Peters and H. Vanbekkum, Recl. Trav. Chim. Pays-Bas-J. Roy. Neth. Chem. Soc., 1977, 96, 315-316.

13 P. R. Zalupski, K. L. Nash and L. R. Martin, J. Solution Chem., 2010, 39, 1213-1229.

14 P. R. Zalupski, K. L. Nash, Y. Nakamura, M. Yamamoto and L. R. Martin, in Actinides 2009. IOP Conference SeriesMaterials Science and Engineering, IOP Publishing Ltd, Bristol, England, 2010, vol. 9.

15 A. Aziz and S. J. Lyle, J. Inorg. Nucl. Chem., 1971, 33, 34073408.

16 G. Geipel, Coord. Chem. Rev., 2006, 250, 844-854.

17 C. Moulin, Radiochim. Acta, 2003, 91, 651-657.

18 J. V. Beitz, J. Alloys Compd., 1994, 207, 41-50.

19 T. Kimura and Y. Kato, J. Alloys Compd., 1998, 271, 867871.

20 T. Kimura, R. Nagaishi, Y. Kato and Z. Yoshida, Radiochim. Acta, 2001, 89, 125-130.

21 W. Runde, C. Van Pelt and P. G. Allen, J. Alloys Compd., 2000, 303-304, 182-190.

22 T. Stumpf, M. M. Fernandes, C. Walther, K. Dardenne and T. Fanghänel, J. Colloid Interface Sci., 2006, 302, 240-245.

23 P. Thouvenot, S. Hubert, C. Moulin, P. Decambox and P. Mauchien, Radiochim. Acta, 1993, 61, 15-21.

24 A. B. Yusov, J. Radioanal. Nucl. Chem., 1990, 143, 287-294.

25 A. Barkleit, G. Geipel, M. Acker, S. Taut and G. Bernhard, Spectrochim. Acta, Part A, 2011, 78, 549-552.

26 B. Raditzky, S. Sachs, K. Schmeide, A. Barkleit, G. Geipel and G. Bernhard, Polyhedron, 2013, 65, 244-251.

27 A. Barkleit, S. Tsushima, O. Savchuk, J. Philipp, K. Heim, M. Acker, S. Taut and K. Fahmy, Inorg. Chem., 2011, 50, 5451-5459.

28 A. Heller, A. Barkleit, H. Foerstendorf, S. Tsushima, K. Heim and G. Bernhard, Dalton Trans., 2012, 41, 1396913983.

29 B. C. Mayo, Chem. Soc. Rev., 1973, 2, 49-74.

30 A. K. Patel and J. D. Joshi, J. Indian Chem. Soc., 1996, 73, 71-73.

31 H. Moll, A. Johnsson, M. Schäfer, K. Pedersen, H. Budzikiewicz and G. Bernhard, BioMetals, 2008, 21, 219228.

32 K. Müller, H. Foerstendorf, S. Tsushima, V. Brendler and G. Bernhard, J. Phys. Chem. A, 2009, 113, 66266632.

33 B. Li, J. Raff, A. Barkleit, G. Bernhard and H. Foerstendorf, J. Inorg. Biochem., 2010, 104, 718-725.

34 M. J. Frisch, G. W. Trucks, H. B. Schlegel, G. E. Scuseria, M. A. Robb, J. R. Cheeseman, G. Scalmani, V. Barone, B. Mennucci, G. A. Petersson, H. Nakatsuji, M. Caricato, X. Li, H. P. Hratchian, A. F. Izmaylov, J. Bloino, G. Zheng, J. L. Sonnenberg, M. Hada, M. Ehara, K. Toyota, R. Fukuda, J. Hasegawa, M. Ishida, T. Nakajima, Y. Honda, O. Kitao, H. Nakai, T. Vreven, J. A. Montgomery Jr., J. E. Peralta,
F. Ogliaro, M. Bearpark, J. J. Heyd, E. Brothers, K. N. Kudin, V. N. Staroverov, R. Kobayashi, J. Normand, K. Raghavachari, A. Rendell, J. C. Burant, S. S. Iyengar, J. Tomasi, M. Cossi, N. Rega, N. J. Millam, M. Klene, J. E. Knox, J. B. Cross, V. Bakken, C. Adamo, J. Jaramillo, R. Gomperts, R. E. Stratmann, O. Yazyev, A. J. Austin, R. Cammi, C. Pomelli, J. W. Ochterski, R. L. Martin, K. Morokuma, V. G. Zakrzewski, G. A. Voth, P. Salvador, J. J. Dannenberg, S. Dapprich, A. D. Daniels, Ö. Farkas, J. B. Foresman, J. V. Ortiz, J. Cioslowski and D. J. Fox, Gaussian 09, Revision A.02, Gaussian, Inc., Wallingford, CT, 2009.

35 C. T. Lee, W. T. Yang and R. G. Parr, Phys. Rev. B: Condens. Matter, 1988, 37, 785-789.

36 A. D. Becke, J. Chem. Phys., 1993, 98, 5648-5652.

37 M. Dolg, H. Stoll, A. Savin and H. Preuss, Theor. Chim. Acta, 1989, 75, 173-194.

38 R. Krishnan, J. S. Binkley, R. Seeger and J. A. Pople, J. Chem. Phys., 1980, 72, 650-654.

39 W. D. Horrocks and D. R. Sudnick, J. Am. Chem. Soc., 1979, 101, 334-340.

40 T. Kimura, G. R. Choppin, Y. Kato and Z. Yoshida, Radiochim. Acta, 1996, 72, 61-64.

41 R. A. Binstead, A. D. Zuberbühler and B. Jung, SPECFIT Global Analysis System, Version 3.0.37, Spectrum Software Associates, Marlborough, MA, USA, 2005.

42 K. Gajda-Schrantz, L. Nagy, T. Fiore, L. Pellerito and T. Gajda, J. Chem. Soc., Dalton Trans., 2002, 152-158.

43 A. Günther, R. Steudtner, K. Schmeide and G. Bernhard, Radiochim. Acta, 2011, 99, 535-541.

44 A. Barkleit, M. Acker and G. Bernhard, Inorg. Chim. Acta, 2013, 394, 535-541.

45 L. D. Pettit, I. Puigdomenech and H. Wanner, Ionic Strength Corrections for Stability Constants using Specific Interaction Theory (SIT), Academic Software, York, UK, 2004.

46 T. Vercouter, B. Amekraz, C. Moulin, E. Giffaut and P. Vitorge, Inorg. Chem., 2005, 44, 7570-7581.

47 K. Spahiu, Ph. D. Thesis, The Royal Institute of Technology Stockholm, Sweden, 1983.

48 I. Grenthe and H. Wanner, in Chemical Thermodynamics of Uranium., Elsevier, Amsterdam, 1992, Appendix B: Ionic strength corrections.

49 L. Ciavatta, Anal. Chim., 1980, 70, 551-567.

50 L. Ciavatta, Anal. Chim., 1990, 80, 255-263.

51 H. C. Helgeson, D. H. Kirkham and G. C. Flowers, Am. J. Sci., 1981, 281, 1249-1516.

52 R. M. Supkowski and W. D. Horrocks, Inorg. Chim. Acta, 2002, 340, 44-48.

53 J. I. Kim, R. Klenze, H. Wimmer, W. Runde and W. Hauser, J. Alloys Compd., 1994, 213/214, 333-340.

54 G. Plancque, V. Moulin, P. Toulhoat and C. Moulin, Anal. Chim. Acta, 2003, 478, 11-22.

55 K. J. Powell and L. D. Pettit, The IUPAC Stability Constants Database, Academic software, York, UK, 2005. 
56 G. A. Gamov, K. V. Grazhdan, M. A. Gavrilova, S. V. Dushina, V. A. Sharnin and A. Baranski, Russ. J. Phys. Chem. A, 2013, 87, 967-972.

57 R. E. Mesmer, W. L. Marshall, D. A. Palmer, J. M. Simonson and H. F. Holmes, J. Solution Chem., 1988, 17, 699-718.

58 Z. F. Gesse, G. I. Repkin, V. A. Isaeva and V. A. Sharnin, J. Therm. Anal. Calorim., 2012, 110, 1457-1462.

59 M. Kakihana, T. Nagumo, M. Okamoto and H. Kakihana, J. Phys. Chem., 1987, 91, 6128-6136.
60 G. B. Deacon and R. J. Phillips, Coord. Chem. Rev., 1980, 33, 227-250.

61 I. Bertini, C. Luchinat and G. Parigi, in Current methods in inorganic chemistry, Elsevier, Amsterdam, 2001, vol. 2 .

62 E. W. Stout and H. S. Gutowsky, J. Magn. Reson., 1976, 24, 389-398.

63 X. Y. Chen, G. S. Goff, W. C. Ewing, B. L. Scott and W. Runde, Inorg. Chem., 2012, 51, 13254-13263. 